Revista Kinesis, Santa Maria v.36, n.3, p. 41-52, set-dez. 2018

Centro de Educação Física e Desportos - UFSM

Revista Kinesis

DOI: $105902 / 2316546434459$

Data de submissão: 25-08-2018

Data de Aceite: 21-11-2018

\title{
PRÁTICAS E AMBIVALÊNCIAS CORPORAIS NA ORLA DA PRAIA DE CAMBURI EM VITÓRIA/ES'
}

\author{
AMBIVALENCES AND BODY PRACTICES ON THE SHORE OF PRAIA DE CAMBURI IN VITÓRIA/ES \\ PRACTICAS Y AMBIVALENCIAS CORPORALES EN LA COSTANERA DE LA PLAYA DE CAMBURI EN \\ VITÓRIA/ES
}

\author{
Rodrigo Esteban Gutiérrez Herrera \\ rodrigo.gutierrez.herrera@gmail.com \\ Universidade Federal da Bahia - UFBA \\ Ivan Marcelo Gomes \\ ivanmgomes@hotmail.com \\ Universidade Federal do Espírito Santo - UFES
}

\begin{abstract}
RESUMO
O presente texto tem como objetivo desvelar questões em relação às práticas corporais e os entendimentos de corpo que têm frequentadores de uma praia na orla da cidade de Vitória/ES. Foi desenvolvida uma pesquisa qualitativa baseada na produção etnográfica. Também foram utilizadas entrevistas dirigidas semiestruturadas das quais se criaram os diferentes eixos de análise. Dentre os principais resultados destacamos como os frequentadores do espaço constroem diferentes entendimentos em torno de um discurso baseado no bem-estar, para assim justificar e construir suas próprias noções de saúde, estética e corpo.
\end{abstract}

Palavras-Chave: Corpo; Saúde; Estética; Etnografia

\section{ABSTRACT}

This paper aims to uncover issues on corporal practices and the understandings of body that have beach goers in the border of the city of Vitória/ES. Thus a qualitative research was developed based on ethnographic production. We also used semi-structured interviews, from which the different axes of analysis were created. Among the main results we highlight how space goers construct different understandings around a discourse based in well being to justify and construct their own notions of health, aesthetics and body.

Keywords: Body; Health; Aesthetics; Ethnography

\section{RESUMEN}

El presente texto tiene como objetivo desvelar cuestiones en relación a las prácticas corporales y los entendimientos de cuerpo que tienen frecuentadores de una playa en la costanera de la ciudad de Vitória/ES. Fue desarrollada una investigación cualitativa basada en la producción etnográfica. También fueron utilizadas entrevistas dirigidas semiestructuradas de las cuales se crearon los diferentes ejes de análisis. Entre los principales resultados destacamos como los frecuentadores del espacio construyen diferentes entendimientos en torno a un discurso basado en el bien estar para así justificar y construir sus propias nociones de salud, estética y cuerpo.

Palabras Clave: Cuerpo; Salud; Estética; Etnografía

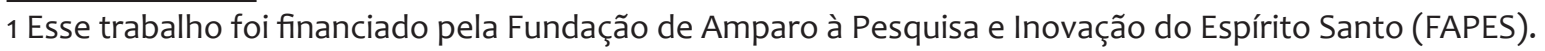




\section{Consideraçõos iniciais}

A praia é um espaço onde há uma diversidade de usos em relação ao corpo, um espaço de diferentes atividades e práticas com seus próprios códigos e entendimentos, mas é, também, uma paisagem que representa uma pequena fotografia de um contexto geral onde podem se apreciar as relações que as pessoas têm com conceitos ao redor do corpo, saúde, estética, bem-estar, entre outros. O espaço encontra-se em um contexto atual da alta modernidade com significados próprios atravessados pelo consumo, a moda, o marketing e inúmeros especialistas. São só alguns dos elementos contextuais em torno da presente pesquisa para entender as relações que envolvem as diferentes pessoas que frequentam a praia. E é aqui onde se enquadra o objeto principal deste texto: os entendimentos que os frequentadores da praia têm em relação ao corpo. O objetivo principal é interpretar esses entendimentos às luzes dos vínculos com os discursos sobre a saúde e o bem-estar presentes no contexto brasileiro.

Como metodologia foi desenvolvida uma etnografia com foco na praia de Camburi no município de Vitória/ES. A pesquisa se baseou na produção etnográfica de Wagner (2010) dividida em dois principais momentos que foram desenvolvidos desde setembro do ano 2017 a fevereiro do ano 2018: em um primeiro momento realizamos a observação e caracterização da orla e das atividades. Foi aqui que começaram a se levantar questões em relação às práticas, a familiarização do campo e uma inserção como um frequentador deste ambiente. Teve também um segundo momento de interação com as pessoas, onde foram desenvolvidas entrevistas semiestruturadas com frequentadores de diferentes atividades e práticas na praia. Como entrevistas semiestruturadas ou direcionadas se trabalhou com um roteiro com questões e perguntas base, sendo que construímos as perguntas em relação a aspectos gerais dos frequentadores, bem como das práticas: o tempo na praia, motivações pessoais e outras justificações. Embora se tenha trabalhado com um roteiro durante a realização destas entrevistas, também foram sendo elaboradas outras questões em função da inserção mais intensa no campo de pesquisa. As intenções dos frequentadores com as práticas e atividades desenvolvidas, assim como, a relação com seus corpos, os quais estão vinculados às influências de uma sociedade voltada ao consumo baseadas na responsabilização individual pelas escolhas disponibilizadas em diferentes instâncias e artefatos (moda, cuidados com o corpo, alimentação, etc) (BAUMAN, 2001).

Desenvolveram-se dez entrevistas com frequentadores de diferentes perfis, idades, atividades e escolaridades. Foram entrevistadas pessoas de escolaridade superior completa, superior incompleta, pós-graduandos e pós-graduados, homens e mulheres entre os 27 e os 73 anos. Moradores de bairros adjacentes à praia, como Jardim da Penha ou Mata da Praia, além de outros municípios da região metropolitana participaram dentro deste grupo. As profissões e ocupações foram diversas também, estudantes 
universitários, auxiliares, aposentados, mecânicos, cientistas, profissionais da saúde, etc. Os frequentadores realizam práticas como corrida, caminhada, ciclismo, slackline, patins, calistenia, natação, surf, futevôlei e atividades de circuito funcional, entre outras.

A discussão dos resultados se derivou em diferentes eixos ou temas de análises. Elaboramos categorias temáticas em função da frequência de alguns elementos presentes nas falas dos frequentadores, como por exemplo, a separação entre praia e academia ou a questão estética, além de objetos frequentes das pesquisas de educação física como corpo, saúde ou sociabilidade. No presente texto se destacaram assim o espaço da praia, a saúde, estética e as noções de corpo no marco do contexto da praia de Camburi às luzes de uma cultura ligada às questões consumo, estilos de vida e modas. A ideia principal foi dialogar entre as ações realizadas pelos frequentadores, seus discursos e os entendimentos relacionados às práticas que desenvolviam, passando assim, inevitavelmente, por estas temáticas (saúde, estética, sociabilidade) nas quais o corpo toma uma posição protagonista. Nesta direção, o artigo foca suas análises em torno de três destes eixos: saúde, estética e corpo.

\section{Saúde no espaço da praia}

Durante as entrevistas observamos e analisamos que, independente das práticas realizadas na orla, um argumento mobilizava as motivações dos frequentadores. Nesse sentido, a escolha estava atravessada por um ponto base explicitado por todos os entrevistados: a saúde. Assim, neste primeiro eixo analítico, iniciamos com questões básicas: “De que saúde eles estão falando? Que tipo de saúde é essa?”.

Nas respostas dos frequentadores da praia, estes indicam a saúde como um valor abstrato que se pode ir ganhando ou perdendo em relação às diferentes práticas ou atividades. Os entrevistados indicam:

Tanto melhoramento como a manutenção mesma da saúde, é essencial [...] vamos supor, se você, fica parado em casa acaba virando um sedentário atrofiando, faz mal, essa é a manutenção para se manter saudável né? (Entrevistado 1).

Eu fiquei, por exemplo, duas semanas fora, duas não, três no interior do Estado e não fiz exercício, quando voltei de lá, foi complicado, já tava bem complicado, tava sentindo muita dor nas pernas, já sentia falta de ar, aí tive que começar aos poucos, mas agora já tô normal (Entrevistado 5).

Isto se encontra em direta relação com as conceitualizações feitas por Costa (2016) em que a saúde é olhada como um valor que não é estritamente fixo, ou seja, a saúde como um valor que vai se perdendo ao longo do tempo e que se pode melhorar ou manter realizando certas ações como os mesmos frequentadores indicaram. Estas 
manutenções corresponderiam a diferentes atividades ou práticas que Santos e Manske (2015) apresentam como os imperativos de saúde. Os imperativos de saúde são diferentes discursos, amparados por diferentes disciplinas e conhecimentos de caráter institucional, propagados assim por diferentes especialistas de medicina, atividades físicas, alimentação, etc.

Interpretamos que as diferentes atividades para o melhora ou manutenção da saúde não estão necessariamente em direta relação com resultados quantificáveis ou de constantes anátomo-biológicas. As atividades relacionadas com a manutenção da saúde não são realizadas simplesmente por serem atividades de caráter prescritivo com gastos calóricos (assim como atividades que mostrem melhoras nestas taxas ou constantes anátomo-biológicas), mas também, os sujeitos procuram atividades que além de serem saudáveis outorguem a possibilidade de experimentar outros tipos de benefícios não mensuráveis. Porém, há também, antes disso, uma questão de desvalorização das práticas consideradas como não saudáveis: não fazer exercício, se alimentar de uma má forma, consumir produtos entendidos como não saudáveis. Há toda uma forma de relacionar estas práticas não saudáveis com uma moral onde radica uma culpabilidade ao não cumprimento destas obrigações, o que também poderia se relacionar com o poder pastoral $^{1}$ e as relações entre frequentadores e os especialistas, médicos, educadores físicos e nutricionistas.

Assim, como foi dito anteriormente, mesmo que a maioria dos entrevistados indica a importância das atividades físicas para o melhoramento da saúde em aspectos anátomofisiológicos, o que Ortega (2008) indica como o sentido organicista relacionado a taxas e caracteres mensuráveis, como por exemplo, nos problemas de caráter médico que eles mencionam como apneia de sono, hipertensão, refluxo entre outras; os frequentadores indicam também um melhoramento da saúde num sentido que podemos entender como ampliado, isto é, em relação a questões além do anátomo-fisiológico. Este sentido ampliado de saúde é difuso e tem relação com as sensações, questões relacionadas à saúde mental, desejos e aspectos que não são estritamente quantificáveis.

Desta forma, os frequentadores não simplesmente relacionam as práticas com um melhoramento nas questões médicas, senão, também, com um se sentir bem, com um estado de ânimo ou relaxamento:

Me sinto melhor, você, quando trabalho, meu trabalho é um pouco estressante [...] aqui você para tira isso da sua mente, você esquece disso aí [...] cê dá uma desligada do mundo, eu chamo higiene mental (Entrevistado 3).

Sim, com certeza, tanto emocional né? O físico mesmo, pra manter a forma senão vem a obesidade né? Vem a depressão, se você fica só em casa e automaticamente você se

10 poder pastoral descrito na obra de Foucault indica como o poder tem formas de racionalidade no contexto do Estado moderno que podem se aplicar à relação que tem professores, médicos e outros especialistas com técnicas individualizantes e ao mesmo tempo comunitárias através de saberes disciplinares. 
vá sentir só e começa a depressão ansiedade né? Caminhada é tudo de bom, esquece tudo (Entrevistada 4).

Em relação ao melhoramento da saúde, é essencial né? Eu pratico por isso, eu acho que não é só questão de saúde física também corporal [...] Pois eu acho que tem a ver também com saúde mental né? Como eu falei com você, é um momento também que eu tô aqui que eu consigo abstrair das minhas questões, enfim, tô mais voltada pra mim (Entrevistada 9).

Estes interesses relacionados ao que chamamos de um estado de bem-estar mostraram ser a principal procura por parte dos frequentadores na hora de fazer atividades, ou seja, as questões relacionadas à saúde estão em direta relação com um se sentir bem. Porém, os estados de bem-estar podem se justificar a partir das múltiplas mensagens difundidas pelos diferentes especialistas, os que proporcionam diferentes caminhos, alguns até ambivalentes. O estado de bem-estar é pessoal e não se encontra totalmente delimitado em virtude das múltiplas mensagens, as que podem concordar e se contradizer ao mesmo tempo.

O tema da saúde apareceu também como um tópico ligado diretamente à presença de um profissional especialista da saúde. Os frequentadores ligam a ação do médico como um dos principais responsáveis para o envolvimento com as práticas corporais. Muitos dos entrevistados indicaram sua entrada às atividades na academia por conta de ordens médicas. Estes amparados em diferentes justificativas relacionadas a constantes anátomo-biológicas mensuráveis (taxas, pressão, colesterol, sangue, triglicerídeos, etc.) indicaram para os frequentadores a necessidade de realizar algum tipo de atividade. Isso fica explicito nas falas dos entrevistados:

Na verdade porque o médico mandou mesmo [...] não porque eu queria não, foi porque o médico mandou [...] foi porque eu tenho problema de refluxo né? então uma das coisas né? Problema digestão, aí o médico pediu pra eu correr ou caminhar porque eu ia melhorar, me disse (Entrevistada 7, grifo nosso).

Eu ia porque precisava até por questão de saúde porque eu estava com a pressão alta então médico exigiu que eu fizesse um exercício né? Porque senão ia piorar minha situação e comecei ir na academia né? (Entrevistada 8, grifo nosso).

As entrevistas e as conversas com os frequentadores durante a incursão etnográfica na praia foram importantes para problematizar as relações de poder que eles mantinham com os especialistas, indicando assim nas suas próprias palavras que os médicos "mandaram", “ordenaram" ou "exigiram", o que desde uma perspectiva foucaultiana, pode se relacionar com o exercício de um poder-saber disciplinar, o poder pastoral.

Por outro lado, estão os frequentadores que na procura deste estado de bemestar levam em consideração outras e difusas mensagens elaboradas por distintos especialistas. Assim, esses frequentadores da praia levam um estilo de vida com diferentes rotinas epráticas em relação a estes imperativos: 
Meu corpo tá habituado a malhar, meu corpo ele pede isso, beber água, se alimentar bem, eu evito comer frituras, eu evito comer frituras, tem um monte de coisas que eu faço hoje...que eu fazia antigamente que eu não faço mais hoje como beber, não bebo mais, eu não como mais frituras, evito coisas que pesam, doces eu não bebo refrigerante não bebo há quatro anos, só suco água mineral, água de coco (Entrevistado 6).

Assim como o entrevistado 6, alguns frequentadores levam em consideração uma série de tarefas que cumprem não somente por conta da saúde, mas em torno do estilo de vida. Desta forma, eles asseguram que "estão acostumados" a esse tipo de rotina saudável ou que seu "corpo pede" esse tipo de alimentação ou exercício, o que também pode levar a uma radicalização nos cumprimentos das tarefas apresentadas pelos diferentes especialistas.

Como foi mencionado anteriormente, muitos dos frequentadores (embora não todos) começaram realizando atividades em academias de ginástica. Para muitos deles foi a porta de entrada para um estilo de vida mais relacionado às práticas. Ainda assim, a maioria dos que alguma vez frequentaram uma academia, acabaram abandonando-a por diversos motivos, relacionados aos limites dessa instituição em relação à diversidade de atividades, caracterizando-a como um espaço fechado, sem sociabilidade, sem atividades grupais, com um caráter estritamente mercantil, assim como também, por não garantir a possibilidade de adequação de diferentes rotinas entre seus frequentadores.

Este tipo de caracterização em relação às academias de ginástica pode ser atribuída a outras instituições, assim como às cidades ou outros espaços urbanos. Aqui, segundo Gonçalves e Alves Júnior (2007), os espaços urbanos são caracterizados como lugares de produtividade, de lucro e ganância desmedida, e também, como lugares de atividades padronizadas. A praia, em contrapartida, embora esteja localizada dentro do espaço urbano, é visada como um lugar dentro da natureza, isto é, com elementos diversos, onde prima o orgânico e que corresponde a um espaço sanitário de cura (GONÇALVES; ALVES JÚNIOR, 2007). Nesta direção, os frequentadores caracterizam a praia como um lugar onde se vivencia o "ar livre", o vento, o espaço aberto no qual existem variadas atividades que escapam da lógica rotinizada e padronizada que atribuem tanto à cidade como às academias de ginástica. A praia, desta maneira e em concordância com Deleuze (1992), entraria em um entendimento de espaço aberto próprio das instituições das sociedades de controle. Essas instituições possuem outro tipo de dinâmica ou maneira de distribuir os indivíduos em espaços abertos, em oposição às sociedades disciplinares descritas por Michel Foucault, onde os indivíduos passavam de um espaço confinado a outro, como é o caso da fábrica. Deleuze (1992) vincula a surgimento destas novas instituições com uma crise das instituições disciplinares tradicionais e seus espaços de confinação, sendo que isto se explicita na rejeição dos indivíduos às instituições modernas e suas formas estritas de disciplinarização dos corpos (escola, prisões, universidades, hospitais, etc.). No espaço aberto da praia são outros os tipos de técnicas exercidas sobre o corpo. Técnicas que, 
segundo Deleuze, são mais difusas e implícitas, onde tanto o corpo como os indivíduos têm um caráter divisível ou individual e que é diferente das sociedades disciplinares e suas instituições tradicionais nas quais o indivíduo estava sempre em relação a um grupo, a uma massa.

Desta maneira, vemos como a saúde se encaixa dentro de justificativas para a realização de práticas, e que são interpretadas não só em termos quantificáveis, senão também, em aspetos relacionados com outros processos subjetivos.

\section{As estéticas da praia}

O segundo eixo que desenvolvemos na pesquisa foi em relação às questões estéticas no contexto das práticas corporais na praia. A maioria dos frequentadores apresentava diferentes juízos de valor em relação a esta questão. Grande parte dos frequentadores entrevistados falou das finalidades estéticas das práticas e atividades corporais com uma rejeição ou como um caráter que não importava para eles. Nenhum indicou diretamente que realizava atividades com uma finalidade inteiramente estética, embora quase todos apresentassem tais finalidades como motivações comuns relacionadas às pessoas que realizam atividade física tanto em espaços como a praia quanto em academias, isto pode ser visto nas seguintes falas:

Você vê que nesse período de pré-carnaval pessoal tá todo fissurado, é corrida, é dieta, ninguém se preocupa no [...] no ano tudo se preocupa com isso, questão de alimentação de atividade física, é só a maioria isso aí nessas datas (Entrevistada 2).

Os jovens gostam muito de academia, porque tem um culto ao físico, tem se valorizado muito o físico né? Então os jovens são muito apegados a isso né? Supervalorizando e também acho que é um pouco de exibição gostam de se mostrar (Entrevistada 4).

A estética é normal, porque é uma consequência do que você faz, mas eu hoje eu pra mim não malho pra minha estética, eu malho pra minha saúde (Entrevistado 6).

Aqui, muitos dos frequentadores faziam uma diferenciação entre as pessoas que realizam atividades desenvolvidas nas academias de ginástica com suas características próprias (rotineiras, repetitivas, etc.) com as outras motivações que têm as pessoas que frequentam a praia para a realização de outras atividades. Nesta diferenciação, as pessoas da academia são caracterizadas, em um grau menor ou maior, como "pessoas que se preocupam demais pela estética", o que está fortemente carregado de juízos de valor expressos explicitamente de diferentes maneiras pelos mesmos frequentadores como algo "negativo". Seriam pessoas que se deixam levar pelos padrões estéticos e os chamados "corpos perfeitos" impostos socialmente.

A procura desta estética está determinada por atividades específicas, focalizadas, 
rotineiras. Atividades que tentam adequar o corpo a certos padrões mensuráveis; padrões fixos quantificáveis que se destacam em, maior ou menor medida, ou volume, certas partes do corpo, com uma marcada diferenciação entre cada gênero, o que se encontra em relação com uma corpolatria exportada dos Estados Unidos (SANT'ANNA, 2005; EDMONDS, 2007). Para Malysse (2007, pg. 93) as mídias da sociedade brasileira produzem um corpo virtual, o qual resulta em um corpo de mentira, medido, calculado e artificialmente preparado para ser traduzido em imagens para assim tornar-se uma poderosa mensagem da corpolatria. Corpolatria influenciada pelas novas modas corporais em constante transformação.

Essa estética influenciou a sociedade brasileira, porém algumas outras características a respeito do imaginário do corpo brasileiro se mantiveram. Para Edmonds (2007, p. 247), há uma experiência de beleza universal que no Brasil sofreria um tipo de refração reafirmando também seus próprios simbolismos relacionados à beleza, como é o caso das coxas grossas e redondas ou as "bundas empinadas". Outras características importantes destacáveis como status no contexto brasileiro de praia seriam os cabelos loiros (EDMONDS, 2007) e a morenidade da pele (FARIAS, 2007). Características que motivariam às pessoas dentro do contexto de praia a tais investimentos.

As motivações estéticas são vistas pelos frequentadores entrevistados como comuns, inevitáveis, como algo "normal” que acontece com as práticas corporais, sobretudo, em relação aos períodos pré-carnavalescos, como afirmam alguns dos entrevistados, onde as pessoas estariam se preparando para se "exibir" durante o período de verão.

Entendemos que podem ser interpretados diferentes tipos de estética (até dentro das mesmas respostas dos frequentadores), mas aqui há uma tendência pela forte e marcada presença da estética das mídias, os constantemente mencionados padrões de beleza ou padrões de corpo. Esta estética das mídias é relacionada pelos frequentadores da praia à vaidade, superficialidade e ego.

Há outro entendimento estético que alguns frequentadores relacionam aos esportes ou outras atividades. Este tipo de estética é relacionada à funcionalidade e as exigências das práticas. Isto pode se apreciar na fala da entrevistada 9:

Naturalmente você adquirindo um corpo que é moldado pelo esporte, se a gente joga aqui na areia, por exemplo, um futebol naturalmente a coxa vai ficar mais definida né? O bumbum vai ficando mais definido um pouco menos os braços, mas ainda assim fica, né? Diferente de academia que você fazer uma atividade direcionada para ficar com braço em caso dos homens sarados (Entrevistada 9).

Este fato de realizar a "prática pela prática", seja pelo gosto, interesse ou competitividade, tem mais aceitação e até admiração para os entrevistados em virtude de estar relacionado com outro tipo de moral e valorização. A prática ao ter outra finalidade não relacionada com a "obtenção" de um corpo padronizado e hegemônico é vista com outro juízo de valor de caráter positivo.

Um exemplo que foi destacável em relação à questão estética foi a fala com o entrevistado 6 ao indicar que: 
Anteriormente era só ser um corpo pra mostrar esteticamente, pra você chegar num lugar e chamar a atenção, eu tinha isso, eu chegava num lugar e gostava que tudo mundo olhasse para mim, que isso encheu meu ego, valorizava meu ser, mas na verdade era um vazio imenso, era só uma coisa minha eu...eu chegava em casa e não tinha nada mas aquilo ali é uma coisa que você quer no momento da época da vida, que achar que ter um corpo você é o cara, chegar num lugar todo mundo te elogia, fala mal fala bem mas fala de você, era aquilo que eu queria, hoje não ligo pra isso, fala mal de mim ou fala bem, não me importa, importa que eu esteja bem, a minha mente mudou pra isso (Entrevistado 6).

Esta foi uma das posturas mais interessantes na pesquisa por conta das próprias reflexões que o frequentador expressou e suas antigas motivações em relação a uma estética padronizada que ele procurava.

Assim, a estética como um eixo de análise, permite problematizar os usos do corpo nos discursos dos frequentadores junto com as problemáticas de saúde. Desta forma, se relacionam de maneira direta com o próximo tópico desenvolvido na pesquisa: como se entendem os corpos nos espaços da praia.

\section{Corpos da praia, Corpos na praia}

Este eixo de análise é um dos mais complexos, embora seja um aspecto ao qual os frequentadores mais se expressam, pois existem diferentes formas de construir ou entender a corporeidade, em relação às diferentes estéticas (como foi analisado no tópico passado). Corpo que não é estritamente delimitado e que se encontra na fronteira de entendimentos contraditórios de saúde, beleza, dietas, conhecimentos científicos, às vezes, aleatórios.

Há certas limitações na hora de usar tais categorias como eixos temáticos. Por um lado o corpo como categoria de análise ou eixo temático estudado pelas ciências sociais e a educação física como um objeto dado e, por outro lado, também as perspectivas dos próprios frequentadores de como eles entendem seus corpos e como o utilizam para elaborar mensagens e justificar suas decisões, subjetividades e desejos alimentados ao mesmo tempo por outras mensagens e perspectivas. Segundo Silva (2001), existe uma visão de corpo relacionado ao mercado e ao consumo:

A gestão do desejo no interior do consumismo que o mercado cria esta ambiguamente vinculada ao ideal cultivado de um ser perfeito, que é permanentemente exigido dos indivíduos; ambíguo porque se deve consumir tudo e, ao mesmo tempo, manter uma postura de controle e autodeterminação, inclusive para se obter o "corpo ideal" [...] Todas as atitudes que se esperam dos indivíduos na transformação das suas dimensões corporais - a dieta, o exercício intenso, a capacidade de suportar a dor e a exaustão - são cobranças de comportamentos que demonstrem a capacidade de autodeterminação e força de vontade, metáforas culturais de uma expectativa normalizante de corpo e comportamentoquereforça, aheteronomiapeladependênciadoOutro(SILVA,2001.p.59) 
Esse argumento pôde ser observado nas falas anteriores relacionadas à saúde ou à estética. A entrevistada 7 outorga uma perspectiva particular em relação a como ela interpreta a relação indivíduos-corpo:

Eu acho que elas têm um corpo [...] porque no caso assim, as pessoas elas gostam muito mostrar o que elas têm né? Então muita gente malha porque querem um corpo bonito, não um corpo saudável, então é assim é como se a gente vivesse num país que rotula o corpo que você tem, você vê um corpo bonito um corpo escultural, tem aquele padrão que você quer seguir, então tipo assim, nosso país ele é praticamente, ele rótulo isso, né? Você tem que ter esse tipo de corpo, então muita gente que não consegue só emagrecer, eles tentam fazer isso na academia, na área no circuito, então acho que é mais estética mesmo, a pessoa é um corpo (Entrevistada 7).

Este tipo de perspectiva enfatiza o corpo como algo dado, onde as pessoas podem se "reduzir" a um corpo outorgando valor, cuidando dele e priorizando-o em relação à mente. Isto está em direta concordância com o que Santos e Manske (2015) chamam de um "eu psicológico interno", o que também pode ser entendido como a separação grega entre soma e psique, ou a perspectiva cartesiana da dualidade alma-corpo. Esta perspectiva fica explícita também nas falas de uma entrevistada que expressa a sua perspectiva de corpo com um olhar desde sua religião cristã:

As pessoas têm um corpo que deve ser valorizado, né? Eu disse que Deus nos criou para sermos felizes e dentro de cada um existe um Deus, né? Deus habita em cada um de nós, e esse corpo tem que ser valorizado, né? Não ser destruído com drogas, com exce...nem o excesso nem de nada, então a vida é importante e temos que cuidar desse corpo que Deus nos deu e ser agradecidos por sermos perfeitos principalmente (Entrevistada 4).

A diversidade de perspectivas mostra como os diferentes elementos (saúde, corpo, beleza, etc.) são entendidos de distintas maneiras pelos frequentadores. Os elementos são utilizados para justificar as ações dos mesmos frequentadores, o que gerencia ou propicia novas subjetividades como é o caso do entrevistado 3:

Eu gosto de andar, de ter disposição, mas não quanto eu corri, quanto que eu andei ou quanto pedalei, sem mensurar distância, entendeu? (Entrevistado 3).

Aquio frequentadorsedesvincula deumaperspectiva emrelaçãoaumaprodutividade e se foca na experiência e no que ele gosta. Tanto estes, como outros exemplos, mostram como a diversidade de perspectivas dos mesmos frequentadores impossibilita uma noção completamente fechada, delimitada, sobre corpo, saúde ou beleza.

Tal fato que abre formas de abordar as pesquisas que não são tão exploradas. $O$ fato de encontrar essa diversidade de argumentos num grupo relativamente heterogêneo, mas pequeno, possibilitou uma interpretação de como as pessoas usam as narrativas das diferentes disciplinas e conhecimentos em relação ao corpo para outorgar um sentido próprio às suas práticas corporais cotidianas. 


\section{Conclusões}

As mensagens e entendimentos relatados, falados e expressados pelos frequentadores da praia mostram a diversidade de elementos que entram em jogo no momento de realizar e justificar uma prática corporal na praia e como estas atividades estão atravessadas por temas como saúde, sociabilidade, estética, além de corpos baseados em uma questão experiencial ou sensível que não se limitam às questões médicas.

Entendemos que a pesquisa foi atravessada por um contexto de evanescentes definições em relação aos entendimentos de produção corporal. Os indivíduos apresentam discursos que resultam de uma mistura, um amálgama de desejos, subjetividades, próprias, externas, internas, pessoais e gerais, os quais vão se complexificando. Corpos em relação a desejos, assim como indivíduos submetidos aos seus próprios desejos e desejos, muitas vezes, submetidos por outros discursos em relação às necessidades sociais como, por exemplo, àquelas vinculadas à saúde.

Os diferentes frequentadores têm por fim um "se sentir bem" ou "melhor" que não se encontra delimitado totalmente, senão que é um terreno amplo e difuso de experiências e atividades que se conectam a diferentes entendimentos disciplinares e não disciplinares, gerando assim uma gama de motivações e justificativas por parte dos mesmos frequentadores.

Este panorama também se refere a um contexto global de alta modernidade, onde há uma multiplicidade de opções baseadas num mercado que muda constantemente em relação às próprias necessidades e atividades dos sujeitos. Entendimentos ambivalentes e contraditórios que jogam em diferentes direções e que não se encontram de forma definitiva e se encaixam como principais justificativas dos frequentadores da praia estudada nesta pesquisa.

\section{Referências bibliográficas}

BAUMAN, Zygmunt. Modernidade líquida. Rio de Janeiro: Jorge Zahar, 2001.

COSTA, Rogério. Políticas da vida e pedagogia do corpo. In: As práticas corporais no campo da saúde: pesquisa interinstitucional e formação e rede. (Org.) CARVALHO, Y.M; GOMES, I.M; FRAGA, A.B. - 1. ed. São Paulo: Hucitec, 2016.

DELEUZE, Gilles. Conversações. Tradução de Peter PálPelbart. São Paulo: Ed. 34, 1992.

EDMONDS, Alexander. No universo da beleza: Notas de campo sobre cirurgia plástica no Rio de Janeiro. In: GOLDENBERG. M et. al. Nu \& Vestido: dez antropólogos revelam a cultura do corpo carioca. $2^{\text {a }}$ ed. Rio de Janeiro: Record, 2007. 
FARIAS, Patrícia. Corpo e classificação de cor numa praia carioca. In: GOLDENBERG. M et. al. Nu \& Vestido: dez antropólogos revelam a cultura do corpo carioca. $2^{\mathrm{a}}$ ed. Rio de Janeiro: Record, 2007.

GONÇALVES, Cleber A. G.; ALVES JÚNIOR, Edmundo D. Entre o mar e a montanha: esporte, aventura e natureza no Rio de Janeiro. Niterói: EdUFF, 2007.

MALYSSE, Stéphane. Em busca dos (H)alteres-ego: Olhares franceses nos bastidores da corpolatria carioca. In: GOLDENBERG. M et. al. Nu \& Vestido: dez antropólogos revelam a cultura do corpo carioca. $2^{\mathrm{a}}$ ed. Rio de Janeiro: Record, 2007.

ORTEGA, Francisco. O corpo Incerto - corporeidade, tecnologias médicas e cultura contemporânea. Rio de Janeiro: Garamond, 2008.

SANT'ANNA, Denise. Cuidados de sí e embelezamento feminino: fragmentos para uma história do corpo no Brasil. In: Políticas do corpo: elementos para uma história das práticas corporais. (Org.) SANT'ANNA, D. - 2ª ed. São Paulo: Estação Liberdade, 2005.

SANTOS, Luis Henrique S.; MANSKE, George S. Política da própria vida, cultura somática e os imperativos contemporâneos de saúde. In: GOMES, I.M; FRAGA, A.B; CARVALHO, Y.M. (org.) Práticas corporais no campo da saúde: uma política em formação - Porto Alegre, Editora Rede Unida, 2015.

SILVA, Ana Marcia. Corpo, ciência e mercado: reflexões acerca da gestação de um novo arquétipo da felicidade. - Campinas, SP: Autores associados: Florianópolis: Editora da UFSC, 2001.

WAGNER, Roy. A invenção da cultura. São Paulo: CosacNaify, 2010. 